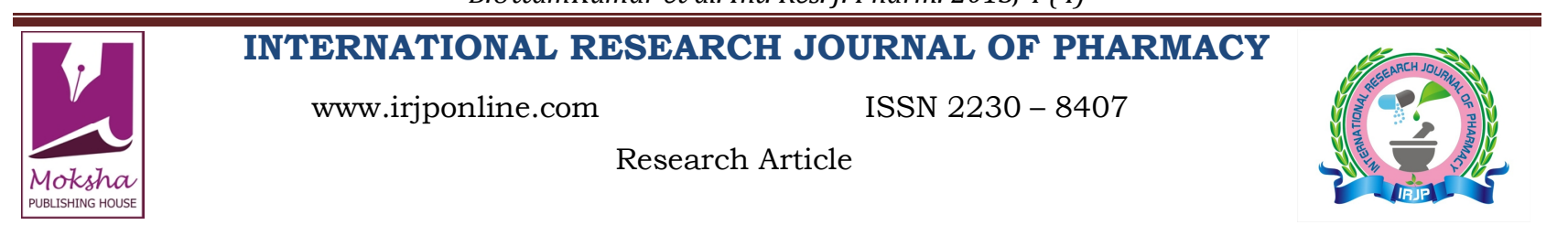

\title{
COMPARATIVE ANTIBACTERIAL ACTIVITIES OF THE COMBINED CRUDE LEAF EXTRACT OF BIXA ORELLANA, AZADIRACHTA INDICA AND OCIMUM SCANTUM
}

\author{
B.UttamKumar*1, A.Bhubaneswari ${ }^{1}$, M.V.VTejasri ${ }^{1}$, P.Radhakrishna ${ }^{1}$, K.D $^{1}$, K.Amrita $^{2}$ \\ ${ }^{1}$ Department of Pharmacology K.G.R.L College of Pharmacy, Andhra University Bhimavaram, Andhra Pradesh, India \\ ${ }^{2}$ Department of Pharmaceutical Analysis, K.G.R.L College of Pharmacy, Andhra University Bhimavaram, Andhra Pradesh, \\ India \\ Email: uttambiswas81@gmail.com
}

Article Received on: 19/02/13 Revised on: 07/03/13 Approved for publication: 11/04/13

DOI: 10.7897/2230-8407.04437

IRJP is an official publication of Moksha Publishing House. Website: www.mokshaph.com

(C) All rights reserved.

\begin{abstract}
In the present paper, we analyze the past, present and future of medicinal plants, both as potential antimicrobial crude drugs as well as a source for natural compounds that act as new anti-infection agents. Ethanol extracts of the leaves of Bixa orellana, Azadirachta indica \& Ocimum scantum were investigated for their invitro antimicrobial properties. Fresh leaves were collected randomly from Bhimavaram region, India. Plants were compared with voucher specimens deposited by Dr. B. Sarveswara Lingam at Department of Botany, K.G.R.L College (Autonomous), Bhimavaram, Andhra Pradesh, India. The aim of study was to scientifically test whether plant used in traditional medicine for the treatment of infection showed antibacterial activity. Extracts of sample of 3 species traditionally used as antibacterial were screened for activity against Esherichia coli, Pseudomonas aeruginosa \& Staphylococcus aurues. The study confirms that simple laboratory methods are very well suited to assess the efficacy of traditionally used medicinal plants to inhibit bacterial growth. A comparison to the traditional uses also indicate that local knowledge can give important leads for the development of new treatments. Further tests, especially with regards to toxicity, are needed to verify the safety of the traditional preparations.

KEYWORDS: Antibacterial activity, Medicinal plants, Bhimavaram, Traditional medicine.
\end{abstract}

\section{INTRODUCTION}

Nature has been a source of medicinal agents for thousands of years and an impressive number of modern drugs have been derived from natural sources, many of these isolations were based on the uses of the agents in traditional medicine ${ }^{1}$

The search for eternal health and longevity and for remedies to relieve pain and discomfort drove early man to explore his immediate natural surroundings and led to the use of many plants, animal products, minerals etc. and the development of a variety of therapeutic agents ${ }^{2}$.

A total of 122 biologically active compounds have been identified, derived only from 94 species of plants. A conservative estimate of the number of flowering plants occurring on the planet is $2,50,000$. Of these, only about $6 \%$ have been screened for biological activity and a reported $15 \%$ have been evaluated phytochemically. Consistent findings should be carried out to discover a probable abundance of medicinal extracts in these plants ${ }^{3}$.

The discovery and development of antibiotics are among the most powerful and successful achievements of modern science and technology for the control of infectious diseases. However, the rate of resistance of pathogenic microorganisms to conventionally used antimicrobial agents is increasing with an alarming frequency $4,5,6$.

In the present study, ethanol extracts of 3 medicinal plants were screened for antimicrobial activity against 3 different standard strains of microorganisms. Further, all the three plant extracts were mixed and screened for antimicrobial activity against 3 standard strains of microorganisms.

\section{MATERIALS AND METHODS \\ Collection of Plant Material}

Fresh leaves were collected randomly from Bhimavaram region, India (K.G.R.L College campus, Dirsumarru Road). The details of the plant/plant parts screened, their families and their locality are given in Table-1 $7,8,9$. Plants were compared with voucher specimens deposited by Dr. B. SarveswaraLingam at Department of Botany, K.G.R.L College (Autonomous), Bhimavaram, Andhra Pradesh, India. Fresh plant materials were washed in tap water, air dried and then homogenized to fine powder and stored in airtight bottles.

\section{Ethanol Extraction}

Thoroughly washed fresh leaves of 3 plants Bixa orellana, Azadirachta indica \& Ocimum scantum of plant materials dried in shade for two weeks \& then powdered with the help of waring blender, $100 \mathrm{gm}$ of shade dried powder was mixed with $250 \mathrm{ml}$ ethanol \& taken in soxhlet extractor for $48 \mathrm{~h}$. The solvent extracts were concentrated under reduced pressure \& preserved at $5{ }^{\circ} \mathrm{C}$ in airtight bottle until further use.

\section{Source of Micro Organism}

The organisms used were Escherichia coli, Pseudomonas aeruginosa, Staphylococcus aurues.organisms were obtained from K.G.R.L Degree microbiology lab \& K.G.R.L pharmacy microbiology lab.

\section{Medium preparation}

Accurately weigh $55 \mathrm{gr}$ of macconkey agar and make up to the volume (1000ml)using distilled water(used for Esherichia coli). Nutrient agar medium is prepared(used for Pseudomonas aeruginosa, Staphylococcus aurues) and the components are Agar (15gr), Beef extract (3gr), Sodium chloride (5gr), Peptone (5gr), make up to $1 \mathrm{lt}$ using distilled water. Above prepared mediums are autoclaved at $121^{\circ} \mathrm{C}$ temperature, $15 \mathrm{lb}$ pressure for 15 minutes.

\section{Stock preparation}

Stock solutions of various organic crude extracts were prepared by mixing well the appropriate amounts of dried extracts and suitable solvent(distilled water)to give rise the 
final concentrations. various concentrations of dried crude extracts are made $1000 \mu \mathrm{g} / \mathrm{ml}, 500 \mu \mathrm{g} / \mathrm{ml}, 250 \mu \mathrm{g} / \mathrm{ml}, 100$ $\mu \mathrm{g} / \mathrm{ml}$.

\section{Determination of antimicrobial activity ${ }^{10}$}

Petri dishes (size $100 \mathrm{~mm}$ diameter) containing $18 \mathrm{ml}$ of cool and molten Agar (at $40^{\circ} \mathrm{C}$ ) were seeded with $100 \mu$ inoculum of bacterial strain (inoculum size was adjusted so as to deliver a final inoculum of approximately $1.0 \times 108$ $\mathrm{CFU} / \mathrm{ml}$ ). Media was allowed to solidify and then individual Petri dishes were marked for the bacteria inoculated. Wells of $6 \mathrm{~mm}$ diameter were cut into solidified agar media with the help of sterilized core borer.

Aliquot $100 \mu \mathrm{l}$ of each extract was poured in the respective well and the plates were incubated at $37^{\circ} \mathrm{C}$ overnight. Solvents (distilled water), in which extracts concentration were prepared, were used as negative control while Streptomycin antibiotic of one unit strength was used as positive control. The experiment was performed in triplicate under strict aseptic conditions. The antibacterial activity for each of the extract evaluated was expressed in terms of the average of the diameter of zone of inhibition (in $\mathrm{mm}$ ) produced by the respective extract at the end of incubation period. Standard deviations were also calculated and represented in the respective table against each extract. An extract was classified as active when the diameter of the inhibition was equal to or larger than $8 \mathrm{~mm}$. All the assays were performed in triplicate and expressed as average values

\section{Determination of minimum inhibitory concentration} (MIC)

The minimum inhibitory concentration (MIC) was determined by comparing the various concentrations of plant extracts which have different inhibitory effect and selecting the lowest concentration of extract showing inhibition. The MIC had done by 96 well U bottom plates. The MIC plates were filled with Macconkey Agar, agar and various concentrations of plant extracts, antibiotics-Streptomycin or solvent control. Finally the MHB medium with overnight test organism (10-8cfu/ml-1) was equally distributed. All the samples were prepared in triplicates and incubated at $37^{\circ} \mathrm{C}$ for $24 \mathrm{hrs}$. The least concentration (highest dilution) of the extract that inhibits colony formationon a solid agar medium after incubation at $37^{\circ} \mathrm{C}$ for $24 \mathrm{hr}$ was considered as MIC.

\section{RESULTS AND DISCUSSION}

The use of antimicrobial agents is critical to the successful treatment of infectious diseases. Although there are numerous classes of drugs that are routinely used to treat infections in humans, pathogenic microorganisms are constantly developing resistance to these drugs ${ }^{11}$ because of indiscriminate use of antibiotics ${ }^{12,13}$.

Results obtained in the present study relieved that the antibacterial activities of Bixa orellana, Azadirachta indica \& Ocimum scantum showed that Ethanolic extract shown good inhibitory activity on the test organisms taking reference Streptomycin as standard drug. The MIC was observed in $100 \mu \mathrm{g} / \mathrm{ml}$ in ethanol extracts \& acetone extracts.

Combination of ethanolic Bixa orellana, Azadirachta indica \& Ocimum scantum extracts shown better antibacterial activity compared to acetone extracts of Bixa orellana, Azadirachta indica \& Ocimum scantum, whereas ethanolic combination extract shown better inhibitory zone compared to individual extract taking referance Streptomycin as standard \& normal saline as control.

Table-1

\begin{tabular}{|c|c|c|c|}
\hline Name of plant & Plant parts & Family & locality \\
\hline Ocimum Scantum & Leaf & Lamiaceae & Dirusumarru (BVRM) \\
\hline Bixa Orellana & Leaf & Bixaceae & K.G.R.L Campus \\
\hline Azadirachta indica & Leaf & Meliaceae & K.G.R.L Campus \\
\hline
\end{tabular}

Table: 2 Minimum inhibitory concentration (MIC) of Bixa orellana, Azadirachta indica, Ocimum scantum \& Streptomycin

\begin{tabular}{|c|c|c|c|}
\hline Compounds & Escherichia coli & Pseudomonas aeruginosa & Staphylococcus aureus \\
\hline Bixa orellana, & 100 & 100 & 100 \\
\hline Azadirachta indica & 75 & 100 & 100 \\
\hline Ocimum scantum & 100 & 100 & 100 \\
\hline Streptomycin & 10 & 10 & 10 \\
\hline \multicolumn{2}{|c|}{ The value of all the compounds is in $\mu \mathrm{g} / \mathrm{ml}$} \\
\hline
\end{tabular}

Table: 3 Combination antibacterial activity (Ethanol Extract)

\begin{tabular}{|c|c|c|c|c|c|c|}
\hline \multirow{2}{*}{ Bacteria } & \multicolumn{3}{|c|}{ Bixa+Neem+Tulsi Leaves Ethanol extract } & \multirow{2}{*}{$\begin{array}{c}\text { Streptomycin (Std) \& } \\
\mathbf{1 0} \boldsymbol{\mu g} / \mathbf{m l}\end{array}$} & $\begin{array}{c}\text { Saline } \\
(\mathbf{C o n t r o l})\end{array}$ \\
\cline { 2 - 6 } & $\mathbf{1 0 0} \boldsymbol{\mu \mathbf { g } / \mathbf { m l }}$ & $\mathbf{2 5 0} \boldsymbol{\mu \mathbf { g }} / \mathbf{m l}$ & $\mathbf{5 0 0} \boldsymbol{\mu \mathbf { g } / \mathbf { m l }}$ & $\mathbf{1 0 0 0} \boldsymbol{\mu g} / \mathbf{m l}$ & $17.6 \pm 0.8$ & $22.3 \pm 0.88$ \\
\hline Escherichia coli & $7.0 \pm 0.57$ & $10.6 \pm 0.8$ & $14.6 \pm 0.6$ & $17.6 \pm 0.8$ & $21.0 \pm 1.5$ \\
\hline Pseudomonas aeruginosa & $6.6 \pm 3.33$ & $11.0 \pm 1.52$ & $13.6 \pm 1.45$ & $0.33 \pm 0.33$ & $0.33 \pm 0.33$ \\
\hline Staphylococcus aureus & $5.00 \pm 0.57$ & $11.6 \pm 1.45$ & $13.6 \pm 1.45$ & $16.0 \pm 1.33$ & $20.3 \pm 1.2$ \\
\hline
\end{tabular}

The values represents mean of sample \pm SD for $n=3$. Diameter of inhibition zone was measured as the clear area centered on the agar well containing the sample.

Table: 4 Combination antibacterial activity (Acetone Extract)

\begin{tabular}{|c|c|c|c|c|c|c|}
\hline \multirow[t]{2}{*}{ Bacteria } & \multicolumn{4}{|c|}{ Bixa+Neem+Tulsi Leaves Acetone extract } & \multirow{2}{*}{$\begin{array}{c}\text { Streptomycin(Std) \& } \\
10 \mu \mathrm{g} / \mathrm{ml}\end{array}$} & \multirow[t]{2}{*}{ Saline(Control) } \\
\hline & $100 \mu \mathrm{g} / \mathrm{ml}$ & $250 \mu \mathrm{g} / \mathrm{ml}$ & $500 \mu \mathrm{g} / \mathrm{ml}$ & $1000 \mu \mathrm{g} / \mathrm{ml}$ & & \\
\hline Escherichia coli & $3.0 \pm 0.57$ & $6.3 \pm 0.8$ & $11.0 \pm 1.5$ & $14.0 \pm 1.5$ & $21.0 \pm 0.5$ & $0.33 \pm 0.33$ \\
\hline Pseudomonas aeruginosa & $2.3 \pm 0.33$ & $4.3 \pm 0.8$ & $10.3 \pm 1.8$ & $12.6 \pm 2.0$ & $22.0 \pm 1.1$ & $0.33 \pm 0.33$ \\
\hline Staphylococcus aureus & $3.3 \pm 0.3$ & $6.0 \pm 0.5$ & $10.6 \pm 0.8$ & $14.3 \pm 0.8$ & $20.3 \pm 1.2$ & $0.33 \pm 0.33$ \\
\hline
\end{tabular}

The values represents mean of sample \pm SD for $\mathrm{n}=3$. Diameter of inhibition zone was measured as the clear area centered on the agar well containing the sample. 


\section{Combination of Ethanol Extract}

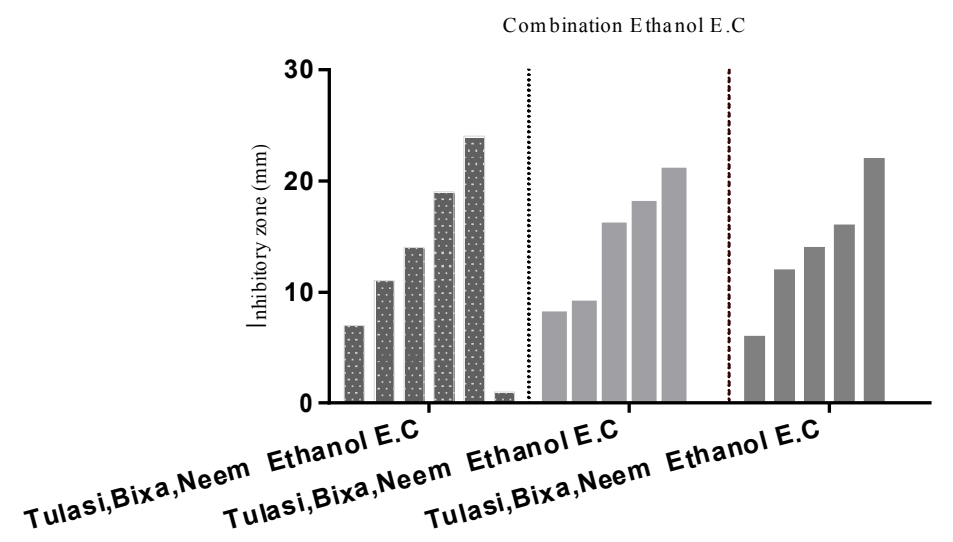

Tulasi,Bixa,Neem Ethanol E.C

Tulasi,Bixa,Neem Ethanol E.C

- Tulasi,Bixa,Neem Ethanol E.C

Combination doses $100,250,500 \& 1000(\mu \mathrm{g} / \mathrm{ml})$

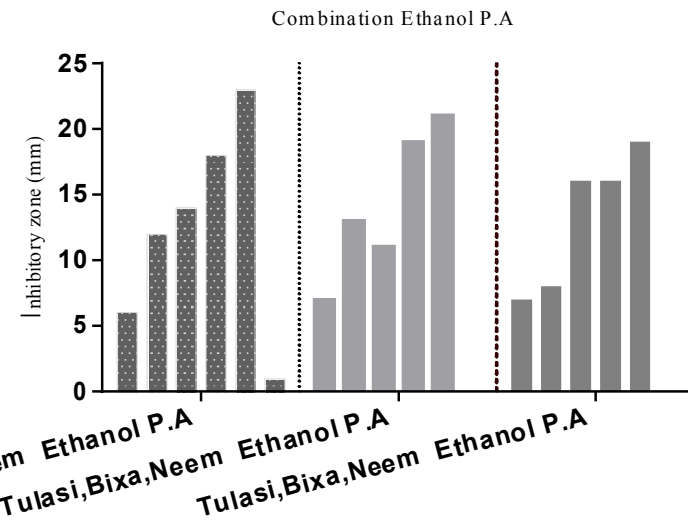

E.:- Tulasi,Bixa,Neem Ethanol P.A

Tulasi,Bixa,Neem Ethanol P.A

- Tulasi,Bixa,Neem Ethanol P.A

Combination doses $100,250,500 \& 1000(\mu \mathrm{g} / \mathrm{ml})$

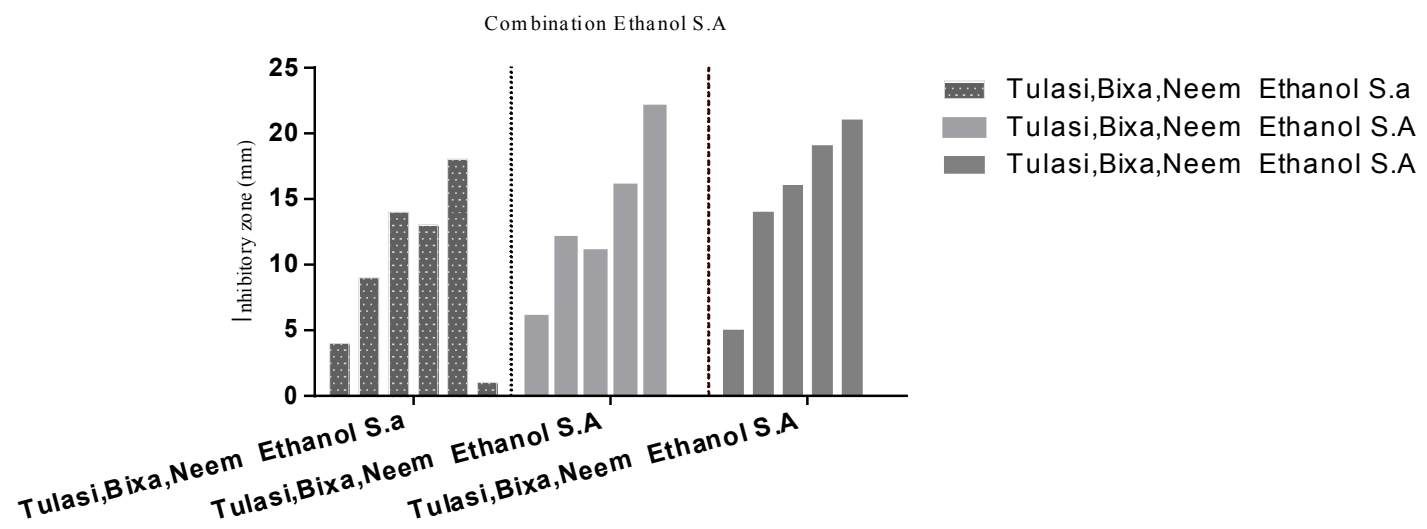

Combination doses $100,250,500 \& 1000(\mu \mathrm{g} / \mathrm{ml})$

Figures: 1-3 (Ethanolic Extracts of Bixa+Neem+Tulsi) \& Streptomycin 10 $\mu \mathrm{g} / \mathrm{ml}$ 
Combination of acetone Extract

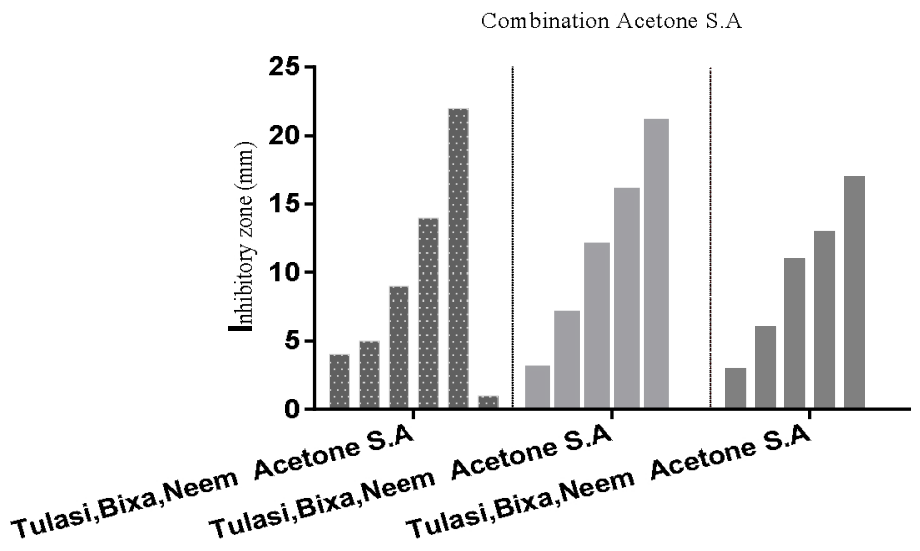

Tulasi,Bixa,Neem Acetone S.A

- Tulasi,Bixa,Neem Acetone S.A

- Tulasi,Bixa,Neem Acetone S.A

Combination doses $100,250,500 \& 1000(\mu \mathrm{g} / \mathrm{ml})$

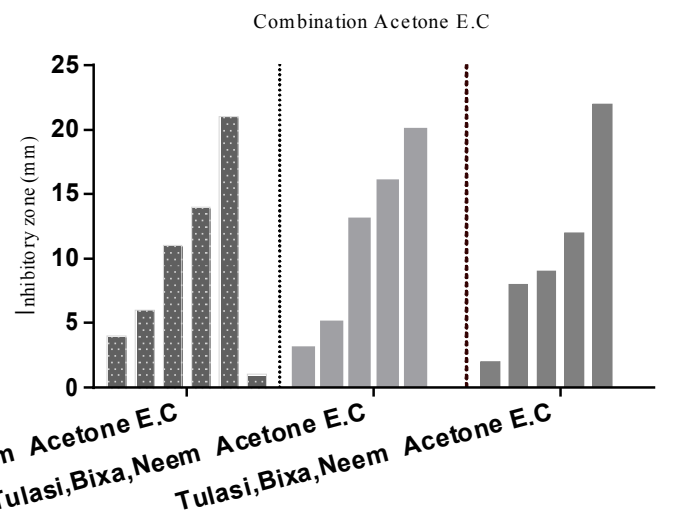

Tulasi,Bixa,Neem Acetone E.C

Tulasi,Bixa,Neem Acetone E.C

- Tulasi,Bixa,Neem Acetone E.C

Combination doses $100,250,500 \& 1000(\mu \mathrm{g} / \mathrm{ml})$

Combination Acetone P.A

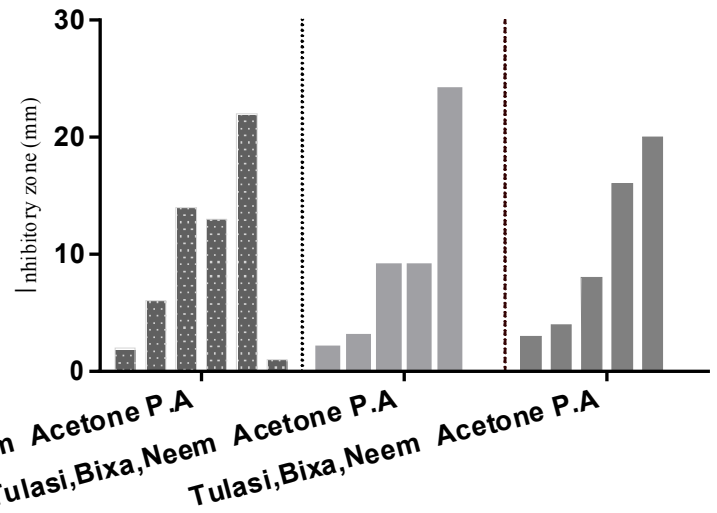

2.:- Tulasi,Bixa,Neem Acetone P.A

Tulasi,Bixa,Neem Acetone P.A

Tulasi,Bixa,Neem Acetone P.A

Combination doses $100,250,500 \& 1000(\mu \mathrm{g} / \mathrm{ml})$

Figures: 4-6(Acetone Extracts of Bixa+Neem+Tulsi) \& Streptomycin 10 $\mathrm{\mu g} / \mathrm{ml}$ 


\section{CONCLUSION}

On the basis of the results obtained, it can be concluded that ethanol \& acetone can be used for extracting antimicrobial compounds from leaves of three plants. The present study shows that ethanolic plant extracts possessed good antimicrobial activity compared to acetonic extracts against bacteria such as Escherichia coli, Pseudomonas aeruginosa \& Staphylococcus aureus. Therefore, it suggests that the plant can be a source of oral drugs to be used in the treatment of opportunistic infections and may be a source for future drug formation.

\section{REFERENCES}

1. Cragg GM, Newman DJ. "Medicinals for the millennia: the historical record". Annals of the New York Academy of Sciences 2001;953: pp325.http://dx.doi.org/10.1111/j.1749-6632.2001.tb11356.x PMid: 11795420

2. Nair R, Chanda S. Antibacterial activities of some medicinal plants of the Western region of India. Turkish Journal of Biology 2007; 31:pp 231-236.

3. Turker AU, Usta C. Biological screening of some Turkish medicinal plant extracts for antimicrobial and toxicity activities. Natural Product Research 2008;22(2): pp136-146. http://dx.doi.org/10.1080/ 14786410701591663 PMid: 18075897

4. Ge Y, Difuntorum S, Touami S, Critchley I, Burli R, Jiang V, Drazan K, Moser H. In vitro antimicrobial activity of GSQ1530, a new heteroaromatic polycyclic compound. Antimicrobial Agents and Chemotherapy 2002;46(10): pp3168-3174. http://dx.doi.org/10.1128/ AAC.46.10.3168-3174.2002 PMCid:128782
5. Nair R, Chanda S. Anticandidal activity of Punica granatum exhibited in different solvents. Pharmaceutical Biology 2005; 43(1): pp21-25. http://dx.doi.org/10.1080/13880200590903309

6. Neogi U, Saumya R, Mishra RK, Raju KC. Lipid content and in vitro antimicrobial activity of oil of some Indian medicinal plants. Current Research in Bacteriology 2008;1: pp1-6. http://dx.doi.org $/ 10.3923 /$ crb.2008.1.6

7. Anjaria J, Parabia M, Dwivedi S. Ethnovet Heritage Indian Ethnoveterinary Medicine - An Overview 1st ed, 2002;Pathik Enterprise, Ahmedabad, India.

8. Sriram S, Patel MA, Patel KV, Punjani NH. Compendium on Medicinal Plants 2004;1st ed. Gujarat Agricultural University, Ahmedabad, India.

9. Khare CP. Indian Medicinal Plants. Springer Science, Business Media, 2007; LLC, New York, USA.

10. Perez, C., Pauli, M. and Bazerque, P. An antibiotic assay by agar-well diffusion method. Acta Biologiae et Medecine Experimentaalis, 1990;15:pp113-115.

11. Al-Bari MA, Sayeed MA, Rahman MS, Mossadik MA.Characterization and antimicrobial activities of a phenolic acid derivative produced by Streptomyces bengladeshiensis a novel species collected in Bangladesh.Respiratory Journal of Medical Sciences2006; 1: pp77-81.

12. Gibbons A (1992) Exploring new strategies to fight drug resistant microbes.Science 257(5073): pp1036-1038. http://dx.doi.org/10.1126 /science.257.5073.1036

13. Rahman MM, Wahed MII, Biswas MH, Sadik GM, Haque ME. In vitro antibacterial activity of the compounds of Trapa bispinosa Roxb. Science 2001;1(4):pp214-216.

\section{Cite this article as:}

B.UttamKumar, A.Bhubaneswari, M.V.VTejasri, P.Radhakrishna, K.D, K.Amrita. Comparative antibacterial activities of the combined crude leaf extract of Bixa orellana, Azadirachta indica and Ocimum scantum. Int. Res. J. Pharm. 2013; 4(4):189-193 